\title{
Simplified Technique of Conventional Cholecystectomy in a Patient with Situs Inversus Totalis: A Case Report from Nepal
}

\author{
Nag SK
}

\begin{abstract}
Introduction: Situs inversus is a rare autosomal recessive disorder occurring in 1:5,000 to 1:20,000 indiviuals. Cholecystectomy is a standard treatment for symptomatic gallbladder stone. We report a case of cholelithiasis in patient with inversus totalis who underwent cholecystectomy. Case presentation: A 48 years old obese female patient with dextrocardia and hypertention presented with a recurrent left upper abdominal pain for two years. Ultrasound abdomen showed gallbladder stone. Conventional cholecystectomy was done with a small left subcostal incision. The postoperative period was uneventful and the patient was discharged on $3^{\text {rd }}$ post operative day. Conclusion: Cholecystectomy is the treatment of choice in patients with a left sided gallbladder stone, like in normal gallbladder and it is safe.
\end{abstract}

Keywords: Conventional cholecystectomy, Gallstone disease, Situs inversus totalis

Author:

1. Dr. Suresh Naag

Address for Correspondence:

Dr. Suresh Kumar Nag

Baishnavi Hospital

Nepalgunj, Banke

Email: sureshnag22@gmail.com

\section{INTRODUCTION}

Situs inversus totalis is a rare autosomal recessive disorder and occurs in 1:8,500 however incidence ranges from 1:5,000 to $1: 20,000 .{ }^{1}$ It is a congenital anomaly in which internal viscera are located in opposite side, and heart is towards right side of chest. Transposed thorasic and abdominal organs are a mirror image of the normal anatomy. Some time it is associated with other congenital anomalies such as kartagener syndrome. ${ }^{2}$ Generally, patients with situs inversus totalis are asymptomatic and have a normal life expectancy.

We reported a case of symptomatic gallstone with hypertension in situs inversus totalis at Baishnavi Hospital, Nepalgunj.

\section{CASE PRESENTATION}

A 48 years old female patient with hypertension presented with a 2 year history of episodic pain over the left upper abdomen and dyspepsia. On examination abdomen was mildly tender in left hypochondrium. Ultrasound abdomen was done which revealed a left sided gallbladder with gallstones. The intrahepatic as well as extrahepatic biliary tracts were normal. Chest x-ray showed dextrocardia (Figure 1). Liver function test and other biochemical parameters were normal. In view of symptomatic gallbladder stone she was planned for cholecystectomy and conventional cholecystectomy was done through a small subcostal incisison under general anaesthesia (Figure 2). Skin, superficial fascia, muscles, and the peritonium were incised. Calot's triangle was dissected carefully; cystic duct and artery were ligated and cut. The gallbladder was removed from its bed and the abdomen was closed in layers. The postoperative period was uneventful. The patient was discharged on the $3^{\text {rd }}$ postoperative day.

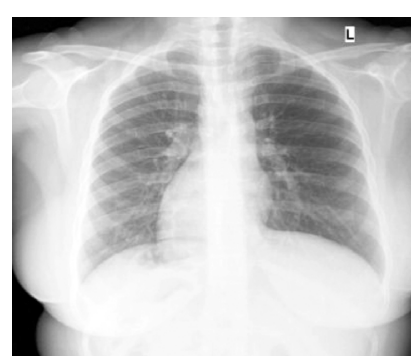

Figure 1: Chest X-ray showing dextrocardia

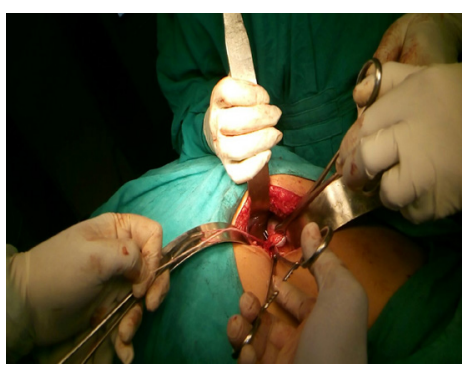

Figure 2: Situs Inversus Cholecystectomy

\section{DISCUSSION}

Cholelithisasis is the most common benign disease of gallbladder. The diagnosis of cholelithiasis is usually based on clinical symptoms and ultrasound abdomen. The left sided gallbladder (LSG) can be found in either in situs inversus or as an isolated finding. It was first reported in $1856^{4}$, who first described the finding on three separate specimens. The finding of left sided gallbladder is a rare congenital anomaly and has a prevalence of $0.1-0.7 \% .^{5}$ Diagnosis of gallstone disease in patients with situs inversus is difficult, especially in those with an unknown history of this condition. Because of the abnormal anatomy of the left-sided gallbladder the clinical presentation of these patients usually involves left upperquadrant pain which is confused with acid peptic disease and 
myocardial Infarction. Laparoscopic cholecystectomy remains the standard operation for treatment of gallstone disease, even in patients with situs inversus. ${ }^{6}$ Due to high blood pressure of the patient we chose conventional cholecystectomy. The type of surgical procedure depends upon the indications, comorbidity, the surgeon's preference, his expertise and patient's choice. Few cases of laparoscopic chlecystectomy has been published even in case of situs inversus cholelithiasis (Table I).

\begin{tabular}{|c|c|c|c|c|c|}
\hline Reference & Country & $\begin{array}{l}\text { Number of } \\
\text { cases }\end{array}$ & Diagnosis & $\begin{array}{l}\text { Patient } \\
\text { position }\end{array}$ & $\begin{array}{c}\text { Operative } \\
\text { time } \\
\text { (minute) }\end{array}$ \\
\hline Arya $^{3}$ & India & 1 & Gall stone & supine & 95 \\
\hline Eisenberg $^{7}$ & USA & 1 & Gall stone & Supine & 85 \\
\hline Patle $^{8}$ & India & 6 & Gall stone & Supine & 65 \\
\hline Fernandes ${ }^{9}$ & Brazil & 1 & Gall stone & supine & $\mathrm{N} / \mathrm{A}$ \\
\hline Hall $^{10}$ & UK & 1 & Gall stone & supine & 65 \\
\hline Lochman $^{11}$ & $\begin{array}{l}\text { Czech } \\
\text { Republic }\end{array}$ & 1 & Gall stone & supine & 70 \\
\hline
\end{tabular}

N/A: not available

Table I: Review of choleleithisais with situs inversus

\section{CONCLUSION}

Like in cholelithiasis with normal anatomy, cholecystectomy in symptomatic gall stone is the standard treartment in situs inversus or isolated left sided gallbladder. Cholecystectomy in these patient is slightly difficult because of abnormal anatomy but it is safe.

\section{REFERENCES}

1. Nursal TZ, Baykal A, Iret D, Aran O. Laproscopic cholecystectomy in a patient with situs inversus totalis. J Laparoendosc Adv Surg Tech 2001; 11: 239-241.

2. Iskandar ME, Radzio A, Krikhely M, Leitman IM. Laparoscopic cholecystectomy for a left-sided gallbladder. World J Gastroenterol. 2013;19:5925-8.

3. Arya SV, Das A, Singh S, Kalwaniya DS, Sharma A, Thukral BB. Technical difficulties and its remedies in laparoscopic cholecystectomy in situs inversus totalis: A rare case report. Int J Surg Case Rep. 2013;4:727-30.

4. Newcombe J.F, Chir M, Henley F.A. Left-sided gallbladder. A review of the literature and a report of a case associated with hepatic duct carcinoma, Arch. Surg. 1964;88(3):494-497 http://dx.doi.org/10.1001/ archsurg.1964.01310210168027.

5. M. Nagai, K. Kubota, S. Kawasaki, T. Takayama, Y. Bandai, M. Makuuchi et al. Are left sided gallbladders really located on the left side? Ann. Surg. 1997;225: 274-280.

6. Phothong N, Akaraviputh $\mathrm{T}$, Chinswangwatanakul V, Trakarnsanga A. Simplified technique of laparoscopic cholecystectomy in a patient with situs inversus: A case report and review of techniques. BMC Surg 2015; 15:23-6.

7. Eisenberg D. Cholecystectomy in situs inversus totalis: a laparoscopic approach. Int Med Case Rep J. 2009;2:27-9.

8. Patle NM, Tantia O, Sasmal PK, Khanna S, Sen B. Laparoscopic cholecystectomy in situs inversus-our experience of 6 cases. Indian J Surg. 2010;72:391-4.

9. Fernandes $M N$, Neiva IN, de Assis CF, Meguins LC, Meguins EM, Fernandes MN. Three port laparoscopic cholecystectomy in a Brazilian Amazon woman with sistus inversus totalis: surgical approach. Case Rep gastroenterol. 2008;2: 170-4

10. Hall TC, Barandiaran J, Perry EP, laparoscopic cholecystectomy in situs inversus totalis: is it safe? Ann R Coll Surg Engl. 2010;92:W30-2

11. Lochman P, Hoffmann P, Koci J. Elective Laparoscopy Cholecystectomy in a 75 years old woman with situs inversus totalis. Videosurgery Miniiv. 2012;7:216-9 